\title{
Does social capital reinforce technological inputs in the creation of knowledge? Evidence from the Spanish regions
}

\author{
By Ernest Miguélez, Rosina Moreno and Manuel Artís ${ }^{1}$ \\ ${ }^{1}$ AQR Research Group - IREA. Department of Econometrics, \\ University of Barcelona. Avda. Diagonal, 690. 08034 Barcelona, \\ Spain. Emails: emiguelez@ub.edu; rmoreno@ub.edu; \\ manuel.artis@ub.edu.
}

\begin{abstract}
In this paper we seek to verify the hypothesis that trust and cooperation between individuals, and between them and public institutions, can encourage technological innovation and the adoption of knowledge. Additionally, we test the extent to which the interaction of social capital with human capital and R\&D expenditures improve their effect on a region's ability to innovate. Our empirical evidence is taken from the Spanish regions and employs a knowledge production function and longitudinal count data models. Our results suggest that social capital correlates positively with innovation. Further, our analysis reveals a powerful interaction between human and social capital in the production of knowledge, whilst the complementarity with R\&D efforts would seem less clear.
\end{abstract}

Key words: social capital, human capital, innovation, complementarities.

JEL codes: C21, J24, O33, R11. 


\section{Introduction}

According to the Lisbon Strategy launched by EU members in 2000, it is Europe's intention to be "the most dynamic and competitive knowledge-based economy in the world capable of sustainable economic growth with more and better jobs and greater social cohesion by $2010^{\prime \prime}$. This strategy is firmly based on innovation as a motor of economic growth and on the learning economy, in order to face the rise of the knowledge-based economy and on-going processes of globalisation. In this framework, the study of the determinants of the European regions' ability to innovate needs to be central to empirical economic research in order to provide policymakers with suitable policy recommendations. Indeed, most of the literature on the determinants of innovation includes R\&D efforts and human capital. However, similar technological input endowments produce dissimilar results across regions, indicating that there must be certain factors that have not fully been taken into consideration. Among these, we believe that social networks, norms, and trust, i.e., social capital, could enable agents to be more effective in achieving their common goals.

In this sense, AUDRETSCH (1998, p. 24) stresses that "political scientists and sociologists have long argued that the differences in the culture of a region contribute to differences in innovative performance across regions" which, in turn, is a leading force driving economic performance, even when knowledge inputs such as R\&D and human capital are held constant. Additionally, SAXENIAN (1990) points out that it is the communication between individuals that facilitates the transmission of knowledge across agents, and not just large endowments of human capital and knowledge in a given economy.

The seminal work by PUTNAM et al. (1993), in which social capital is defined as referring to features of social organization, such as trust, norms, and networks that 
facilitate coordination and cooperation for mutual benefit within a society, means a turning point in the empirical research in this field. Since that date, several scholars have taken these social features into account in producing certain economic outcomes, including productivity, economic growth, and institutional performance, among others (Coleman, 1988; Putnam et al., 1993; HelliWell, 1996; KNACK and KeEFER, 1997; HelliWell and Putnam, 2000; ZaK and KNACK, 2001; SABAtini, 2005; BeUgelsdiJK and VAN SCHAIK, 2005).

In such a setting, the aim of this paper is to analyse the determinants of innovation within Spanish regional economies, focusing our attention on an assessment of the extent to which certain social and cultural features might enhance innovation, and the ways in which this might occur. The idea of social features, like cooperation, trust, civic behaviour, etc., as a source of innovation and, in turn, as a source of competitiveness and growth, is not new. In fact, a major contribution was made by scholars within the literature of Marshallian industrial districts (BECATTINI, 1979; PORTER, 1990, and the like), whilst the literature examining regional and national innovation systems (LUNDVALL and JOHNSON, 1994; EdqUIST, 1997; PAVITT, 1998; SAXENIAN, 1994) has widely stressed the influence of external effects such as formal institutions and informal organizations and networks in the innovation processes of a given economy.

Within the empirical framework given by a knowledge production function (KPF), we test several hypotheses regarding the possible influence of social capital on innovation (measured here by patent applications) in Spanish regions. First of all, we test the hypothesis that the higher the level of social capital, the higher the innovation outcomes will be within a given economy. Then, we test whether social capital exerts its influence on technological progress through certain complementarities with human capital and R\&D efforts. Finally, in line with a number of scholars (DURLAUF and FAfChAMPS, 2004; LYON, 2005; AKÇOMAK and TER WEeL, 2007; PÉrez et al., 2005), we 
examine the idea that the influence of social capital on economic outcomes and innovation differs depending on the level of development of each economy.

Our main results suggest that there is an interesting, and fairly marked, direct impact of social capital on innovation outcomes, while we also detected a strong effect of this asset through its interaction with other technological inputs such as R\&D efforts and, in particular, human capital. Thus, the influence of human capital and R\&D efforts on innovation increases with growing levels of social capital. Moreover, other additional results of interest can be drawn from our empirical research, namely that the influence of social capital varies with the level of development of each region. Within high-income regions, the direct impact of social capital on innovation outcomes is strong, while the complementary effect both with human capital and R\&D efforts is large and significant. However, this is not the case for low-income regions, where the direct impact, although fairly important, is smaller than that for high-income regions, whilst complementarities between inputs are almost negligible.

An additional contribution of this paper is the use of an interesting, complex databank on social capital created by the Valencian Institute for Economic Research (IVIE hereafter). Thus, compared with other simpler measures that have been considered up to now in the literature on social capital (crime rates, teenage pregnancies, several indicators from the Values Surveys, etc.), the measure used in this paper seeks to overcome some of the empirical problems that commonly arise in this field of research due to an endemic lack of consensus on its definition and, therefore, a chronic deficit of suitable data.

The present paper is organized as follows. Section two reviews the related literature on social capital and innovation, sets out the main hypothesis by which social capital and its interactions with other innovation inputs may foster knowledge creation, and 
presents our empirical model. Section three describes our database, providing some descriptive analysis. Section four highlights our results. Finally, section five concludes.

\section{Related literature, theoretical hypothesis and empirical model}

\subsection{Social capital and innovation}

As Coleman (1988, p. 98) stresses, social capital includes "a variety of different entities, with two elements in common: they all consist of some aspect of social structures, and they facilitate certain actions of actors (...), making possible the achievement of certain ends that in its absence would not be possible." Essentially, then, social capital may affect innovation by improving the efficiency of a given economy through a reduction in transaction costs (MASKELL, 2000). In this framework, we presume that there exist several mechanisms whereby such social features -trust, networks, shared values, norms, and so on- embedded in social relationships will foster creativity and, therefore, the creation of innovation.

Seeking to identify the causal nexus between social capital and innovation, DE CLERCQ and DAKHLI (2004) are the pioneers in setting up an empirical relationship between them at an aggregate level. According to these authors, networks foster innovation because they expose individuals to different ideas and provide them with different, as well as useful, information sources too. Indeed, social networks enable individuals to share certain information to know where they can exploit business opportunities, with a high degree of technological content, increasing the number of successful entrepreneurship projects. 
Another interesting point stressed by KNACK and KEEFER (1997) states that higher levels of social capital imply lower monitoring costs related to the misconduct and nonfulfilment of other partners, so firms can devote more time and money to other useful activities, such as innovation. Furthermore, as KAASA et al. (2007) and ACKÇOMAK and TER WEEL (2007) set out, high levels of trust in a given society imply that its members, including investors, are less risk averse. Thus, they can invest more in R\&D, which is usually considered a risky and uncertain activity, producing more innovation outcomes.

Moreover, trust in a country's institutions and legal system is also important. Where the legal system is reliable, especially as regards the protection of new innovations (intellectual property rights), inventors and investors enjoy better incentives to innovate and invest in innovation projects, because they know that their results will receive better protection (DE CLERCQ and DAKHLI, 2004).

Finally, according to several scholars, the main source of innovation creation may well be knowledge flows between individuals, firms and even regions (ROMER, 1986, 1990; AUDRETSCH and FELDMAN, 1996; ANSELIN et al., 1997). In this context, social capital can foster knowledge flows within a given economy, becoming an important indirect source of innovation. As MASKELL (2000) has pointed out, the competitiveness of the knowledge-based economy is based not on costs and prices, but on dynamic improvements, creating and, particularly, diffusing knowledge more speedily than its competitors. According to MASKELL (op. cit.), market failures occur because of asymmetric information in the exchange of knowledge between individuals -in the same way as between firms, which can only be overcome when market relationships are replaced with exchange agreements based on trust.

Having said this, and contrary to the neoclassical conception of knowledge as a public good which is transmitted without costs - especially within the economy of new 
telecommunications, AUDRETSCH and FELDMAN (1996) have pointed out that information transmission costs may not vary with distance, as the neoclassical view says, but rather knowledge transmission depends upon geographical proximity and the frequency of contacts between individuals. Indeed, information is codified and is easily transmitted by means of telecommunications, but knowledge is tacit and its transmission requires human interactions (AUDRETSCH, 1998; PAVITT, 1998). Whereas the latter tradition has assumed that knowledge flows freely within a given economy and at a cost between economies, we assume not only that geography matters, but also that the quality of human contacts can influence knowledge transmission (both codified and tacit knowledge) within a given regional economy. As BRESCHI and LISSONI (2001) have stressed, knowledge is better endowed in individuals, who, in turn, know and trust others, who meet frequently, and with whom they can exchange certain kinds of economic information. In short, ties between individuals based on a relationship of trust ease and accelerate the exchange and search for information (KAASA et al., 2007); and trust enhances cooperation between firms and other patenting institutions, which favours not only the adoption of new manufacturing procedures, but also the sharing of confidential information (DE CLERCQ and DAKHLI, 2004). Given these arguments, the first hypothesis we seek to verify here empirically is that social capital really does encourage the attainment of higher innovation outputs at the regional level.

\subsection{Complementarities between social capital and the inputs of innovation}

A second aim of this paper is to verify the extent to which there exists a relationship of complementarity between social capital and the rest of the inputs in a knowledge production function when determining innovation outcomes. Our underlying theoretical hypothesis states that innovation inputs such as human capital and innovative efforts in the form of R\&D expenses, for instance, might see their influence on the innovation 
results reinforced in societies with a high degree of trust and a broad spread of social networks.

Thus, on the one hand, the complementarity hypothesis implies that, aside from the direct effect of R\&D efforts on innovation outcomes, the effectiveness of these expenditures could be reinforced by social capital. Indeed, for a given regional economy, higher levels of social capital facilitate a more effective diffusion of knowledge which spills over from R\&D expenditures in one firm or organization to other firms and patenting institutions. Thus, the higher the level of social capital in a given region, the higher the R\&D returns should be on innovation. Further, such complementarity could be further reinforced if it yields to a better implementation of public policies and programmes, such as the R\&D expenditure of the public administration and higher education sectors (ACKÇOMAK and TER WEEL, 2007). The latter authors, for instance, have investigated the role played by social capital and structural European funds on innovation activity and economic growth by focusing on Objective 1 regions between 1990 and 2002. Their investigation suggests that in that period European funding did not influence innovation and economic outcomes, whereas social capital did. In seeking to identify statistical complementarities between innovation inputs, they reveal that regions with higher levels of social capital (among the least developed) were more likely to make effective gains from European programmes. Thus, as the authors suggest, social capital appears to be an instrument for the effective implementation of government programmes.

On the other hand, as DE CLERCQ and DAKHLI (2004) point out, higher levels of social capital may enhance opportunities of human capital to promote and value its returns. For SCHULLER (2001), there is an established consensus concerning the role of human capital on economic outcomes, whilst the success of social capital is not as clear as that of the former, due to its novelty and, lamentably, to its vagueness. Nonetheless, 
this author points out several useful tools for analysing the interesting relationship between human and social capital in boosting economic outcomes. Thus, social capital has to be understood as a relationship, a property of the group rather than that of the individual. As SCHULLER (2001) stresses, individuals and their human capital are not discrete entities that exist separately from the rest of the organisation, or from other social units. Thus, the value of the abilities and skills of individuals depends upon the social context within which they are embedded (Op. cit.). His analysis highlights one important conclusion, namely, human capital may include both social and technical skills, but social capital encompasses social networks and social values through which these human skills are built, deployed and rewarded (SCHULLER, 2001).

Besides, PIAZZA-GEORGI (2002) has claimed that whereas physical capital was the main source of economic growth for theorists, human and social capitals, and the interactions between them, nowadays serve as the explanation for better economic outcomes. This author asserts that there is a clear relationship between social and human capital. Thus, although social capital may influence economic performance by reducing transaction costs, it might also have an indirect effect through the realization of ability and entrepreneurship, reducing the costs of human capital investment. Hence, there exists a relationship of complementarity between both forms of capital. Finally, according to the EUROPEAN COMMISSION (2003) although human capital may influence economic performance, needless to say that the knowledge embedded in human beings is acquired in a social process of learning within the family, the school, the workplace, civic social networks, and the like. Thus, according to this report, both social and human capitals reinforce each other and, in turn, may foster economic growth and other economic outcomes. 


\subsection{The knowledge production function framework}

As GRILICHES (1979, 1991a), JAFFE (1989) and FELDMAN (1994) showed, the knowledge production function is an interesting tool for relating innovation efforts, such as R\&D expenditures (RD) and human capital (HK), and some social and structural features of each region (Z), with an innovation output, namely the number of patents (PAT) produced in region $\mathrm{i}$ in a time period $\mathrm{t}$ :

$$
P A T_{i t}=F\left(R D_{i t}, H K_{i t}, Z_{i t}\right)
$$

Specifically, the aforementioned authors proposed a Cobb-Douglas specification on the basis of its usefulness,

$$
P A T_{i t}=R D_{i t}^{\beta_{1}} \cdot H K_{i t}^{\beta_{2}} \cdot Z_{i t}^{\beta_{3}}
$$

It is worth noting that R\&D expenditures can include both public and private investments, and the inclusion of the human capital variable may allow us to control for the ability of certain regions to innovate due to the skills and knowledge embodied in individuals and to control for their absorptive capability. Thus, we expect a positive and significant parameter both for R\&D efforts and human capital. $Z$ is a set of variables used to control for differences in the extent to which regions are prone to innovation because of certain cultural, social and structural factors. Among these, we included a social capital indicator (SK), as we explain below, in order to determine its hypothetical impact on innovation outputs, so again we expect a positive and significant coefficient. Additionally, we included the share of manufacturing employment (MAN) of each region to control for the relative importance of manufacturing sectors in each economy since, 
as has been widely discussed, industrial activities are more likely to patent their results, so a positive and significant sign is also expected.

Moreover, given that working with aggregated data leads to the need for controls for various innovation patterns, we included several variables to capture the composition of the economic activity in each region, in view of the fact that this can determine the effectiveness of innovation in such economies. Specifically, in order to take into account MAR-externalities, which are linked to the existence of a pool of specialized labour, the location of customers and suppliers, and physical and institutional infrastructures, we calculated a specialization index (Spln) for each region ${ }^{2}$, which we would expect to have a positive sign. We included the population density (POP) of each region so as to take into account different regional dimensions as well as agglomeration economies, and a time trend, in order to capture changes in our patent equation owing to the economic cycle. A time lag of one year was considered for all the explanatory variables in order to infer causality from correlation between these and the dependent variable. In fact, in the case of R\&D expenditures, GRILICHES (1991b) points out that firms apply for patents in the early stages of their research, so a one year lag might be an appropriate length of time - since the endogenous variable refers to patent applications and not patents granted. Hence, the specification we estimate empirically is given by

$$
\begin{aligned}
& P A T_{i t}=\beta_{0}+\beta_{1} \cdot \ln \left(R D_{i t}\right)+\beta_{2} \cdot \ln \left(H K_{i t}\right)+\beta_{3} \cdot \ln \left(S K_{i t}\right) \\
& +\beta_{4} \cdot \ln \left(M A N_{i t}\right)+\beta_{5} \cdot \ln \left(S p I n_{i t}\right)+\beta_{6} \cdot \ln \left(P O P_{i t}\right)+\delta \cdot t+\varepsilon_{i t}
\end{aligned}
$$

where $\varepsilon_{\text {it }}$ is a random error term. 


\subsection{Count data modelling}

An important question at this juncture is the nature of the endogenous variable, which is a count variable (nonnegative integers). Thus, a count model specification is preferred here to a linear model, which is what has been used most widely to date (Hausman et al. 1984; Del Barrio-Castro and García-Quevedo, 2005; GumbauALBERT and MAUDOS, 2007). Indeed, unlike the classical regression model, the response variable is discrete, with a distribution that places a probability mass at nonnegative integer values only. Such count models are nonlinear with properties and special features connected to their discreteness and nonlinearity. The basic model for this estimation (CAMERON and TRIVEDI, 2005) is a Poisson regression model which assumes that the dependent variable follows a Poisson distribution. Nevertheless, such a Poisson model, although fairly consistent, assumes equality between the conditional mean and the conditional variance of the endogenous variable. However, there are certain symptoms of overdispersion present in our dependent variable, i.e., the conditional variance exceeds the conditional mean, which has similar consequences to that of the failure of the assumption of homoskedasticity in the linear regression model. In this context, numerous authors have proposed alternatives to control for this overdispersion, with the negative binomial model, which arises from a natural formulation of the heterogeneity between observations (GREENE, 2001), being the most typical. Such a model can be obtained in many different ways, although the mixture distribution is one of the oldest and most widely applied. Moreover, the explanatory variables have been taken in logarithms in order to interpret the associated parameter of each variable as elasticities (CAMERON and TRIVEDI, 1998).

To meet our purposes, equation (3) enables us to assess, by the estimation of a model of this kind, the direct effect of social capital on innovation. Nevertheless, in order to test our second hypothesis, i.e. the complementarity relationship between social capital 
and the innovation inputs, we include interaction terms in the equation, so as to take into account these indirect effects through the parameter of each interaction as follows,

$$
\begin{aligned}
& P A T_{i t}=\beta_{0}+\beta_{1} \cdot \ln \left(R D_{i t}\right)+\beta_{2} \cdot \ln \left(H K_{i t}\right)+\beta_{3} \cdot \ln \left(S K_{i t}\right)+\beta_{4} \cdot \ln (S p I n)_{i t}+\beta_{5} \cdot \ln (M A N)_{i t}+ \\
& \beta_{6} \cdot \ln \left(P O P_{i t}\right)+\beta_{7} \cdot\left[\ln \left(S K_{i t}\right) \cdot \ln \left(H K_{i t}\right)\right]+\beta_{8}\left[\ln \left(S K_{i t}\right) \cdot \ln \left(R D_{i t}\right)\right]+\delta \cdot t+\varepsilon_{i t}
\end{aligned}
$$

\section{Data and descriptive analysis}

\subsection{Social capital indicators and descriptive analysis}

Since the definition of social capital remains elusive and particularly vague, just how it is measured becomes the most controversial issue in each research study that attempts to deal with it. Prior research conducted into social capital has tackled this lack of data by introducing certain kinds of environmental proxies, such as crime rates, teenage pregnancy, blood donation, and so on, which has served to add to the confusion as to just what social capital is, as something different from its outcomes (SABATINI, 2006), and so have arisen mounting econometric problems concerning most empirical studies.

After PUTNAM et al. (1993) presented their definition (i.e., trust, norms, and networks that facilitate coordination and cooperation), much of the literature on social capital has employed data from the World/European Values Survey ${ }^{3}$, in keeping with KNACK and KEEFER's (1997) influential study as these data fitted the earlier definition very well. Thus, the empirical literature has tended to focus on one question in this survey, that is: "Generally speaking, would you say that most people can be trusted or that you need to be very careful in dealing with people?". Responses are then aggregated to obtain regional or country levels of trust -together with other social capital features. However, 
according to some scholars (GLAESER et al., 2000; SABATINI, 2006), this question and the whole survey is not appropriate at the aggregate level, since responses reflect the particular position of those being interviewed, and as such its aggregation fails to capture certain historical and social circumstances. Moreover, the variation in responses might be due to numerous factors, such as "differences in beliefs about the trustworthiness of a common set of people; differences in interpretation of who comprises "most people;" differences in the interpretation of what it means to be able to trust someone; or differences in the ability to elicit trustworthy behaviour from other people" (GLAESER et al., 2000; p. 815). Additionally, as KNACK and KEEFER (1997) acknowledged, the World/European Values Survey has several mistakes and presents an overrepresentation of certain social groups. Furthermore, its statistical representation at low levels of aggregation (for instance, at NUTS 2 level for Europe) is not worthwhile.

Here, therefore, we have opted to use a complex and interesting measure proposed by PÉREZ et al. (2005). According to these authors, current social capital measures do not result from a process of investment, as do other kinds of capitals - namely physical and human capital. Following DURLAUF and FAFCHAMPS (2004) recommendations, who stress the lack of explicit modelling of the process by which social capital is created within societies, the authors of the PÉREZ et al. (2005) database developed one of the most rigorous approaches to the theoretical economic concept of social capital. Indeed, the social capital measure of this database emulates other capital's estimation methodology, including physical capital, since it is based on a model that combines individual trust decisions at the micro level, with the aggregate effect of co-operating being connected within networks in social relationships (PASTOR and TORTOSA-AUSINA, 2007) focusing their analysis on the economic aspects of life (since economic relationships between individuals are the most important sources of interaction and trust creation $)^{4}$. 
Before further analysis, we need to focus on several features that typify the evolution in the Spanish regions' social capital productivity. The useful work undertaken by PÉREZ et al. (2005) provides us with a social capital databank which supplies us with temporal, as well as regional, data. Thus, unlike much of the literature that estimates knowledge production functions with the inclusion of social capital, IVIE's dataset allows us to perform a panel data model ${ }^{5}$. As observed in Figure 1, from minimum levels of social capital recorded in 1985 up to the present day, this variable has undergone a gradual increase, as a result of the rise in well-being within the Spanish regions. Despite this increasing trend, however, social capital plummeted abruptly during the early nineties, coinciding with the recession suffered by the European Monetary System. Nonetheless, a vigorous recovery was recorded during the second half of the nineties up to the end of our period of analysis.

[Insert figure 1 about here]

Surprisingly, social capital differences between Spanish regions are more marked than for other forms of capital in the Spanish case (PÉREZ et al., 2005). Indeed, as can be seen in Figure 2, social capital services are larger in the north-east (the Basque Country, Navarre, Cantabria, Aragon, Balearic Islands, and Catalonia) than in the centre, south, and west, with the exception, of course, of Madrid.

[Insert figure 2 about here] 


\subsection{Variables and databases}

ROGERS (1998) defines innovation as the application of new ideas to the products, processes or to any other aspect of a firm's activity, concerning the process of commercialising and extracting value from ideas. In such a setting, patents have widely been used as a measure of innovation. In spite of their obvious caveats - not all inventions are patented and neither do they have the same economic impact, (GRILICHES, 1991b), equally not all patents are a commercially exploitable innovation, they do present the minimal standards of novelty, originality and potential profits, and as such they should be a good proxy for economically profitable ideas (BOTAZZI and PERI, 2003). We, therefore, use the information on patent applications provided by the European Patent Office (EPO) at the NUTS 2 level $^{6}$. In our period of analysis, 19892001, Figure 3 shows an increasing trend in the number of patent applications per capita, which has become particularly since 1996. However, not all regions have contributed equally to the level of patenting activity in Spain. Thus, as can be seen in Table 1, two regions (Madrid and Catalonia) accounted for more than $50 \%$ of the patents applied for in Spain during our period of analysis.

[Insert figure 3 about here]

As discussed in the literature, we proxy R\&D efforts by means of regional R\&D expenditure, both private and public - thus also including higher education and public administration expenditure. These data are available from the Spanish National Statistics Institute (INE) in a regional (NUTS 2) disaggregated level from 1987 to 2001 at current prices, so the dataset has been appropriately deflated ${ }^{7}$. Data on human capital are provided by IVIE, and the variable was proxied by the percentage of workers with further and below-further education over the total number of workers. 
[Insert table 1 about here]

A number of interesting features can be observed in Table 1. Once again, the regions of Catalonia and Madrid account for more than $50 \%$ of R\&D expenditure during the whole period of analysis. They in turn spent more than $150 €$ per capita in 2001 , a similar level of expenditure to that of Navarre and the Basque Country. Thus, as has often been noted, Spanish innovative activity -both in terms of inputs and outputs- is strongly concentrated. However, since larger cumulative increases in R\&D expenses have occurred in regions outside those of Madrid and Catalonia, a process of technological spread within Spain should become apparent. Finally, as can be seen in Table 1, certain regions, such as Madrid, the Basque Country, Navarre, Aragon, Castile and Leon and Catalonia present the highest levels of human capital.

As for the controls, we calculated our specialization index (Spln) using data on sectorial Gross Added Value from BDMORES databank ${ }^{8}$, from which we also collected data concerning manufacturing employment (MAN). Data describing population and squared kilometres (POP) were also taken from the Spanish National Statistics Institute (INE).

\section{Results}

\subsection{Impact of social capital on innovation: both direct and indirect links}

Using the empirical model described above, we present the results of the negative binomial model estimations of the effects of social capital on innovation outcomes, namely patent applications. Similarly, we expect significant interactions between innovation inputs. It might be argued, as discussed above, that social capital affects innovation outcomes primarily, and perhaps exclusively, through interaction with other 
technological inputs. Hence, if the estimated coefficient on the interaction between social and human capital is positive, the effect of human capital on innovation will be greater, the larger the amount of social capital there is in a given regional economy. Similarly, the effect of social capital on innovation will be greater, the larger the amount of human capital there is in the given region. The same would be true for the interaction between social capital and R\&D efforts.

Our main results are presented in Table 2 -and the tables included thereafter. We present our results beginning with the simplest specification, column (i), first without including any interaction terms, and then we gradually introduce them. Moreover, we performed a Hausman test (HAUSMAN, 1978), and the null hypothesis that individual effects are uncorrelated with the independent variables could not be rejected, so the generalized least squares estimator for the random effects model is consistent and efficient.

The results in column (i) show a positive and significant effect of both R\&D efforts and human capital on innovation, with elasticities of $32.3 \%$ - at the $1 \%$ level of significance and $73.6 \%$ at the $5 \%$ level of significance, respectively. The value of the former is consistent with prior research findings, being only slightly higher than the results reported in MORENO et al. (2005) -20\%- for the European regions, and in line with CABRER-BORRÁS and SERRANO-DOMINGO (2007) - 33\% - and DEL BARRIO-CASTRO and GARCÍA-QUEVEDO (2005) - 40\% - for the Spanish regions. Meanwhile, human capital elasticity is comparable to the results reported by CABRER-BORRÁS and SERRANODOMINGo (2007) -75\% - and GUMBAU-ALBERT and MAUDOS (2007) - 85\% - for the Spanish case, RONDÉ and HUSSLER (2005) - 60\% - for the French regions, or BOTAZZI and PERI (2003) -92\%- for the European regions. Interestingly, the elasticity of patent applications with respect to social capital is significant, so according to our results, social capital exerts a direct influence on innovation outcomes, around $73.7 \%$, in line 
with studies that used the World Values Survey (HAUSER et al., 2007; ACKÇOMAK and TER WEEL, 2007, 2008), and comparable with the importance of human capital, as has been stressed elsewhere (HAUSER et al., 2007). The parameter describing the share of manufacturing employment is also positive and significant, so more industrialized regions tend to innovate further. In the case of the controls, the specialization index is not significant, although it presents the expected positive sign -however, the specialization index would be significant at $16 \%$ and, what is more, it is significant for most of the specifications in subsequent tables, thus indicating that highly specialised regions tend to innovate further as well. The time trend shows a positive and significant parameter, whereas population density does not.

However, as mentioned, social capital might also exert an indirect impact on innovation, thereby reinforcing the effect of human capital. In other words, social capital might affect innovation outcomes by means of the social valuation of human capital, thus acting as an environmental externality which facilitates the achievement of certain ends, in this case innovation outcomes, which in its absence would be achieved at greater social costs. Taking this idea into consideration, in the second specification we, therefore, included the interaction between social and human capital. Although innovation inputs are positive and significant, the interaction term is negative. However, in order to assess the importance of the interactions between inputs accurately, we report total semi-elasticities in equations with interactions terms -thus, adding the complementarity effect to the direct effect- following the formulas given in the lower panel of Table 2. With this aim in mind, we tested the joint significance of both parameters -the direct effect and its indirect effect through its interaction with human capital for which standard errors for the total semi-elasticities were calculated using the delta method (SERFLING, 1980). Here, since the covariance of the parameter of each variable and the parameter of their interaction were negative, the total semi-elasticities of each innovation input could well be significant even though the initial parameters are 
not significant. As can be observed in column (ii) of Table 2, the total semi-elasticity of patents with respect to social capital remains statistically significant at $1 \%$, and around nine points greater than in the first specification. Moreover, the total semi-elasticity on innovation with respect to human capital, which increases its significance up to $1 \%$, rises from a value of 73.6 to $86 \%$. Such an interesting result leads us to corroborate our hypothesis regarding the complementary roles between human and social capital, as has been stressed by several authors (SCHULLER, 2001; PIAZZA-GEORGI, 2002). Thus, human capital returns on innovation could be stronger in a high social capital environment, which reinforces the valuation of human capital in a given regional economy.

The specification in column (iii) includes the interaction term between R\&D efforts and social capital, whereas the interaction term in column (iv) includes both simultaneously. Albeit that the significance of all parameters - R\&D efforts, human capital and social capital - is obvious, the total semi-elasticities and their standard errors were recalculated. As a result, both human and social capital show significant values and enhanced total semi-elasticities - in particular the former - whilst the total semielasticity of R\&D, although always strongly significant, was not enhanced because of the addition of the complementary effect with social capital.

Given this set of results, we can conclude that features such as trust, social networks and relationships, shared values and the like, exert an important and strong effect on the generation of innovation within a given regional Spanish economy. Moreover, there is strong evidence that social capital reinforces the effect of human capital since higher levels of social capital may enhance opportunities of human capital to promote and value its returns. However, this is not the case for R\&D given that social capital does not seem to enhance the effectiveness of R\&D expenditure. In short, we forwarded the hypothesis that social capital would also reinforce R\&D returns on innovation, since it 
could enhance R\&D expenditures that spill over into other patenting organizations, but at first sight the empirical evidence does not indicate this. Therefore, we chose to verify the hypothesis that social capital will exert its influence through public R\&D expenditures alone, and not through private expenditures. In this instance, we should obtain a significant complementary relationship between social capital and public R\&D, but not with business R\&D.

\section{[Insert Table 2 about here]}

The first four columns of Table 3 show the regression results when entering business and public R\&D efforts separately. By doing so, we were able to explore whether there was an additional effect of social capital resulting from an improvement in the effectiveness of public investments and expenditures, in contrast with that produced by private investments. First of all, our estimations show a more marked effect of human capital on innovation outcomes through its direct influence than is shown in the first specification in Table 2, and the same is true for social capital. Thus, both human and social capitals are significant factors when explaining patenting activities. Interestingly, the effect of public R\&D efforts is strongly significant, whereas that of business R\&D is not. This is consistent with the previous literature, as can be seen in DEL BARRIOCAstro and García-Quevedo (2005) and CABRER-Borrás and SeRrano-Domingo (2007) for the Spanish case, where only public R\&D is reported as exerting a significant influence on the generation of innovation outcomes. This scenario might be attributable to the efforts made by the public administrations of those European countries (such as Spain) that lag somewhat behind the leaders, efforts that are aimed at reducing the technological gap between the core and the periphery of Europe (RODRIGUEZ-POSE, 2001). In these countries, public investments are the driving force behind technological innovation. 
Our main conclusions following the introduction of these interactions are similar to those in Table 2, although a number of slight differences are worth noting. Firstly, the strengthening in the effect of human capital on innovation when the interaction term with social capital is included is again marked -around 11 points- and the same is also true for social capital. By contrast, and more interesting for our purposes here, the effect of the interactions with the R\&D efforts of business and public administrations are not very marked. Here again, we find that the total semi-elasticity of public R\&D is strongly significant whereas that of business R\&D is not. However, the interaction of public R\&D with social capital does not seem to increase the returns obtained with such R\&D, as we hypothesized above. Therefore, we find no evidence in favour of social capital as an instrument for a more effective implementation of public R\&D expenses. However, the effect of social capital when interactions with R\&D efforts are included rises by around three points. Thus, our earlier suggestions regarding the complementary impact between public R\&D and social capital can only be partially accepted in the case of the Spanish regions.

[Insert Table 3 about here]

\subsection{Regional heterogeneity in the effect of social capital}

Here, we are interested in determining whether the impact of social capital is related to the level of development achieved in a given economy. Two hypotheses have been forwarded in this respect. First, according to several scholars (LYON, 2005; AKÇOMAK and TER WEEL, 2007), social capital may act as a substitute for the lack of those inputs that foster innovation and other economic outcomes. Thus, in certain economies, with low levels of R\&D expenditure and a certain lack of human skills, social capital might have a greater impact than in more developed economies with better endowments of innovative efforts and human capital. Second, some other authors (PÉREZ et al., 2005) 
have highlighted that the potential gains from a reduction in transaction costs due to better social capital endowments should be more significant in developed regions, technically and technologically complex, where uncertainty and strategic interaction are higher, so there exist greater incentives to trust others. With the aim of verifying which hypothesis holds for the Spanish case, our empirical strategy involved dividing our sample into two sub-samples, containing high-income and low-income regions respectively (Table 3 , columns $\vee$ to $x$ ii). By doing so, we were able to test these hypotheses, and at the same time, by including both public and private R\&D efforts in our regressions, we were able to explore more thoroughly whether there is any complementary effect between social capital and certain types of R\&D expenditures, or whether we have to reject definitively our assumption above.

Thus, the sample was divided according to the per capita Gross Added Value, in such a way that those regions with a per capita GAV above the national mean were included in the high-income sample ${ }^{9}$. According to Table 3 , a marked effect of social capital on innovation outcomes is observed both in high-income and low-income regions. Nevertheless, the value of its elasticity is almost two times greater in the former than in the latter, initially corroborating the hypothesis that relates better social capital returns with more developed regions.

Similarly, in Table 3 (high-income regions, column v), significant parameters for public R\&D efforts are observed. Whereas business R\&D efforts were non-significant, the parameter of public R\&D efforts was strengthened when the interaction between this input and social capital was included -around a seven-point gain. Thus, finally, a highly marked complementary role between social capital and public R\&D efforts was found in high-income regions. This expenditure type includes, among others, the spending of public autonomous bodies, and the expenditure of public firms and universities. It would seem, then, that public expenses devoted to R\&D would be better implemented 
if certain social features (in this instance, chiefly trust and networks) were high and, for example, more collaborative scientific projects were to be carried out -which is an essential source of knowledge diffusion and creation. In general, according to this finding, it might be thought that an improvement in knowledge transmission between research institutions and individuals and firms occurs in high-income regions.

On the contrary, in low-income regions (Table 3 , columns ix to xii), although public R\&D efforts exert an influence on innovation outcomes as well, we only found a slight complementarity effect, since the influence of social capital on innovation outcomes is only increased by around two points, while public R\&D expenses remain the same.

In the case of the human capital in high-income regions, which is strongly significant and high, the interaction between social and human capital reinforces the explanatory power of the latter in a marked fashion. In the low-income regions, human capital is similarly strongly significant and high, though unlike the rich regions, the interaction between this input and social capital does not enhance the explanatory power of human capital. This result suggests that in more developed regions, the potential gains from the presence of higher levels of social capital are greater than in less developed regions. Therefore, human capital returns on innovation would be reinforced by the existence of higher levels of social capital in the former regions. This is not the case, however, for low-income regions, where the potential gains for human capital of the existence of social capital are not so great.

In short, interesting conclusions can be drawn from an analysis of Table 3 (columns $v$ to xii). First of all, social capital fosters innovation and knowledge diffusion directly, both in high- and low-income regions, although its direct impact is greater in the former. However, within high-income regions, an interesting complementary effect between social capital and public R\&D efforts is observed, while a strong complementary effect 
of social capital in interaction with human capital is also recorded. In other words, the effect of human capital and public R\&D efforts is reinforced in highly developed regions, which at the same time present the highest levels of social capital.

By contrast, within low-income regions, neither the interactions between public R\&D efforts and social capital nor between human and social capital reinforce the impact of these technological inputs on innovation due to the existence of complementarities. Thus, within poor regions, social capital may play an important direct effect and a negligible complementary effect with the rest of the inputs. Nevertheless, when a region reaches a minimum threshold of development, social capital has a greater direct impact and may obtain better technological outputs thanks to its relationship with human capital and public R\&D efforts.

\section{Concluding remarks}

In this paper we have set out to analyse the role played by certain social features within a given Spanish regional economy, such as its level of trust, its social networks and the strength of its social ties, its shared values and norms, and the like, in the process of knowledge creation within those regional economies. Specifically, we have estimated a knowledge production function with the inclusion of social capital as a source of innovation. As a proxy for social capital, we have considered an interesting and complex measure that seeks to overcome some of the problems that characterize social capital empirical research. What is more, the main features of this dataset chiefly, its level of disaggregation and time range- and the characteristics of the dependent variable (a non-negative integer) have enabled us to carry out a negative binomial regression within a panel data model at the NUTS2 level of regional disaggregation, adding consistency to our findings. 
According to our empirical approach, we observe that such social features exert a direct influence on innovation outcomes in the Spanish regions. Moreover, we have analysed other mechanisms through which social capital may foster knowledge creation. By introducing interaction terms between social capital and human capital, and between social capital and R\&D efforts, we can conclude that such innovation inputs could see their influence on the innovation output reinforced in societies with a high degree of trust and a broad spread of social networks. In fact, we have obtained strong evidence of the complementarity of the former, since social capital fosters human capital returns on innovation, but our evidence of the latter is negligible. These results might have important policy implications, since they would reject those policy streams that focus their efforts on individuals in order to obtain certain economic outcomes, but which tend to neglect collective learning and relational development.

Likewise, we have tried to understand the low or almost inexistent complementary effect between R\&D expenses and social capital, by introducing business and public R\&D efforts separately so as to analyse the potentially different impact of social capital on innovation through different types of R\&D. Specifically, we have forwarded the hypothesis that, since sometimes the Government is not able to organize the efficient delivery of public goods and services, and by extension, public investments and expenditures, social capital may be an instrument for their effective implementation (DURLAUF and FAFCHAMPS, 2004; ACKÇOMAK and TER WEEL, 2007). However, there seem to be no grounds to support our suggestions, since the interaction between public R\&D and social capital does not appear to increase the returns obtained with such R\&D, as we had hypothesized.

With the aim of taking a step forward in the analysis of the impact of social capital on innovation, we have tested the hypothesis that social capital may have different effects depending on the level of development of each region, and specifically, in terms of the 
different impact of each kind of R\&D efforts in each group of regions. We have analysed whether in less developed economies social capital might act as a substitute for certain technological inputs or whether social capital might play a more prominent role in more highly developed regions due to their larger technical and technological complexity. Our findings suggest that social capital fosters innovation and knowledge diffusion directly, both in high-income and low-income regions. However, the complementarities between social capital and the remaining factors are strong in highincome regions, but insignificant in their low-income counterparts. Thus, our findings support the hypothesis that states that social capital plays a greater role, both directly and indirectly, in high-income regions because of their greater technical and technological complexity compared with that of low-income regions, and that this improves social capital returns on innovation.

To sum up, this paper has shown that social capital can be a decisive factor in the creation and diffusion of knowledge, both directly and by improving the effectiveness of other technological inputs including R\&D efforts and, above all, human capital. Thus, this social externality embodied in human relationships would seem to facilitate the achievement of certain ends, which in its absence would not be possible, such as the creation, acquisition and diffusion of useful knowledge.

However, our study is not without its limitations. First, our measure of innovation (number of patent applications), aside from the aforementioned caveats, might suffer a spurious correlation with social capital. Indeed, social capital may have an impact on innovation creation and diffusion by enhancing not codified (or explicit) knowledge (such as patents), but rather tacit knowledge. Thus, further research is needed to identify a better tacit knowledge proxy. But, given the high and significant coefficient found, we can assume that the enhanced creation and diffusion of tacit knowledge may indeed affect the creation and diffusion of codified knowledge. Second, we have not 
taken into account several dimensions of social capital. As PUTNAM (2000) argues, bonding social capital involves strong and redundant ties, albeit more reliable ones that might carry superfluous information. Meanwhile, bridging social capital entails less reliable ties that carry non-redundant information, which usually link people from different backgrounds and sources of knowledge. Here again, additional research is needed in order to overcome this situation and to identify the differential impact of these social capitals on innovation.

\section{Acknowledgements}

We would like to thank Josep-Lluís Carrión-i-Silvestre, Enrique López-Bazo, Fabio Manca, Jaume Puig-Junoy, Vicente Royuela, Fernando Sánchez-Losada, and Esther Vayá for their helpful suggestions and comments. Ernest Miguélez acknowledges financial support from the Universities and Research Commissioner of Innovation, Universities and Firm Department of the Catalan Autonomous Government and from the European Social Fund. Rosina Moreno and Manuel Artís acknowledge financial support from the Ministerio de Ciencia y Tecnología, Programa Nacional de I+D+I, SEJ2005-07814/ECON and SEJ2005-04348/ECON respectively. 


\section{References}

Acs Z., ANSELIN L. and VARgA A. (2002) Patents and innovation counts as measures of regional production of new knowledge, Research Policy, 31, p. 1069-85.

AKÇOMAK I. S. and TER WEEL B. (2007) How do social capital and government support affect innovation and growth? Evidence from the EU regional support programmes, UNU-MERIT Working Papers, 2007-009.

AKÇOMAK I. S. and TER WEEL B. (2008) Social capital, innovation and growth: Evidence from Europe, IZA Discussion Paper No. 3341.

ANSELIN L., VARGA A. and ACS Z. (1997) Local Geographic Spillovers between University Research and High Technology Innovations, Journal of Urban Economics, 42, p. 422-48.

AUDRETSCH D. B. (1998) Agglomeration and the location of innovative activity, Oxford Review of Economic Policy, 14 (2), p. 18-29.

AudRETSCH D. B. and FELdMAN, M. P. (1996) R\&D Spillovers and the geography of innovation and production, The American Economic Review, 86 (3), p. 630-40.

BALtAGI B. H. (2005) Econometric analysis of panel data. John Wiley \& Sons Ltd, Sussex

BECATTINI G. (1979) Dal "settore» industriale al "distretto» industriale. Alcune considerazioni sull'unità di indagine dell'economia industriale L'Industria, Rivista di economia e politica industriale, 1, p. 7-21. 
BEUgELSDIJK S. and VAN SCHAIK T. (2005) Differences in social capital between 54 Western European regions, Regional Studies, 39 (8), p. 1053-64.

BOTTAZZI L. and PERI G. (2003) Innovation and spillovers in regions: Evidence from European patent data, European Economic Review, 47, p. 687-710.

BRESCHI S. and LISSONI F. (2001) Knowledge spillovers and local innovation systems: A critical survey, Industrial and Corporate Change, 10 (4), p. 975-1005.

CABRER-BORRÁS B. and SERRANO-DOMINGO G. (2007) Innovation and R\&D spillover effects in Spanish regions: A spatial approach, Research Policy, 36, p. 1357-71.

CAmeron A. C. and TRIVEDI P. K. (2005) Microeconometrics. Methods and applications, Cambridge University Press, New York.

Cameron A. C. and TRIVedi P. K. (1998) Regression Analysis of Count Data, Econometric Society Monograph, 30, Cambridge University Press.

Coleman J. S. (1988) Social capital in the creation of human capital, The American Journal of Sociology, 94, p. 95-120.

De CleRcQ D. and DAKHLI M. (2004) Human capital, social capital, and innovation: A multi-country study, Entrepreneurship and Regional Development,16 (2), p. 107-28.

Del BARRIO-CAStRo T. and GARCÍA-QueVEDo J (2005) Effects of University research on the geography of innovation, Regional Studies, 39 (9), p. 1217-29. 
DURLAUF S. N. and FAFCHAMPS M. (2004) Social capital, NBER Working Paper Series 10485 National Bureau of Economic Research.

EdQUIST C. (Ed.) (1997) Systems of innovation: technologies, institutions, and organizations, Printer, London.

EUROPEAN COMMISSION (2003) Building the knowledge society: social and human capital interactions, Commission Staff Working Paper.

FELDMAN M. (1994) The Geography of innovation, Kluwer, Dordrecht.

Glaeser E. L., LAibson D. I., Scheinkman J. A. and Soutter C. L. (2000) Measuring trust, Quarterly Journal of Economics, 115 (3), p. 811-46.

Gumbau-Albert M. and MAudos J. (2007) Patents, technological inputs and spillovers among regions, Applied Economics, 99999(1), p.1-14.

GREene W. H. (2001) Análisis econométrico. Prentice Hall, Madrid.

GRILICHES Z (1979) Issues in assessing the contribution of research and development to productivity growth, The Bell Journal of Economics, 10 (1), p. 92-116.

GRILICHES Z. (1991a) The search for R\&D spillovers, NBER Working Paper No 3768, National Bureau of Economic Research.

GRILICHES Z. (1991b) Patent Statistics as Economic Indicators: A Survey, NBER Working Papers 3301, National Bureau of Economic Research. 
HAUSMAN J.A., HALL B.H. and GRILICHES Z. (1984) Econometric models for count data with an application to the patent-R\&D relationship, Econometrica, 51 (4), p. 909-38.

HAUSMAN J.A. (1978) Specification test in econometrics, Econometrica, 46, p. 1251-71.

Hauser C., TAPPeiner G. and WALDE J. (2007) The Learning Region: The Impact of Social Capital and Weak Ties on Innovation, Regional Studies, 41 (1), p. 75-88.

HeLLIWELL J. F. (1996) Economic growth and social capital in Asia, NBER Working Paper 5470.

HeLLiWell J.F. and PUtNAM R. D. (2000) Economic growth and social capital in Italy, in DAsgupta P. and Seragilden I. (Eds) Social Capital: A Multifaceted Perspective, p. 253-266. World Bank, Washington DC.

JAFFE A. B. (1989) Real effects of academic research, The American Economic Review ,79 (5), p. 957-70.

KAAsA A., KALdARU H. and PARTS E. (2007) Social capital and institutional quality as factors of innovation: evidence from Europe, Working Paper Series of the University of Tartu, Estonia.

KNACK S. and KEEFER P. (1997) Does social capital have an economic pay-off? A cross country investigation, Quarterly Journal of Economics, 112, p. 1251-88.

LUNDVALL B.Å. and JOHNSON B. (1994) The Learning Economy, Journal of Industry Studies, 1 (2), p. 23-42. 
LYON T. P (2005) Making capitalism work. Social capital and economic growth in Italy, 1970-1995, Nota di Lavoro 70.2005, Fundazione Eni Enrico Mattei.

MASKell P. (2000) Social Capital, Innovation and Competitiveness, in BARON S. (Ed) Social Capital: Critical Perspectives. Oxford University Press, Oxford.

MORENO R., PACI R. and UsAI S. (2005) Geographical and sectoral clusters of innovation, Europe Annals of Regional Science, 39, p. 715-39.

PAVITT K. (1998) The social shaping of the national science base, Research Policy, 27, p. $793-805$.

PAstor J. M. and Tortosa-Ausina E. (2007) Social Capital and Bank Performance. An International Comparison for OECD Countries, Documento $\mathrm{n}^{\circ}$ 4/2007 Fundación BBVA.

Pérez F., Serrano L., Montesinos V. and Fernández J. (2006) Measurement of social capital and growth. An economic methodology, Documento $n^{\circ} 4 / 2006$, Fundación BBVA.

Pérez F., Montesinos V., Serrano L. and Fernández J. (2005) La medición del capital social: una aproximación económica. Fundación BBVA, Bilbao.

PIAZZA-GEORGI B. (2002) The role of human and social capital in growth: extending our understanding, Cambridge Journal of Economics, 26, p. 461-79.

PORTER M. (1990) The Competitive Advantage of Nations. Mc-Millan, London. 
PutNAM R. D. (2000) Bowling Alone: The Collapse and Revival of American Community. Simon \& Schuster, New York.

Putnam R., LeOnARDI R. and NAnetti R. (1993) Making Democracy Work: Civic Traditions in Modern Italy. Princeton University Press, Princeton.

RODRÍGUEZ-POSE A. (2001) Is R\&D investment in lagging areas of Europe worthwhile? Theory and empirical evidence, Papers in regional science, 80, p. 275-95.

Rogers M. (1998) The definition and measurement of innovation, Melbourne Institute of Applied Economic and Social Research, Working Paper no. 10798, University of Melbourne.

Romer P. M. (1990) Endogenous Technological Change, Journal of Political Economy, 98 (5), S71-102.

ROMER P. M. (1986) Increasing Returns and Long-run Growth, Journal of Political Economy, 94 (5), p. 1002-37.

RONDÉ P. and HUSSLER C. (2005) Innovation in regions: What does really matter?, Research Policy, 34, p. 1150-72.

SABAtini F. (2006) The Empirics of Social Capital and Economic Development: A Critical Perspective, Nota di Lavoro 15.2006, Fondazione Eni Enrico Matei.

SABATINI F. (2005) The Role of Social Capital in Economic Development. Investigating the Causal Nexus through Structural Equations Models, University of Rome, La Sapienza. Department of Public Economics, mimeo. 
SAXENIAN A. (1994) Regional Advantage. Culture and Competition in Silicon Valley and Route 128, Harvard University Press, Cambridge MA.

SAXENIAN A. (1990) Regional Networks and the Resurgence of Silicon Valley, California Management Review, 33, p. 89-111.

SCHUlleR T. (2001) The Complementary Roles of Human and Social Capital, in The Contribution of Human and Social Capital to Sustained Economic Growth and WellBeing, International Symposium Report edited by the OECD and HRDC.

SERFLING R. J. (1980) Approximation theorems of mathematical statistics, Wiley cop., New York.

ZAK P. J. and KNACK S. (2001) Trust and growth, The Economic Journal, 111, p. 295321. 
Figure 1. Evolution of social capital services in 1995 constant $€$. Spain.
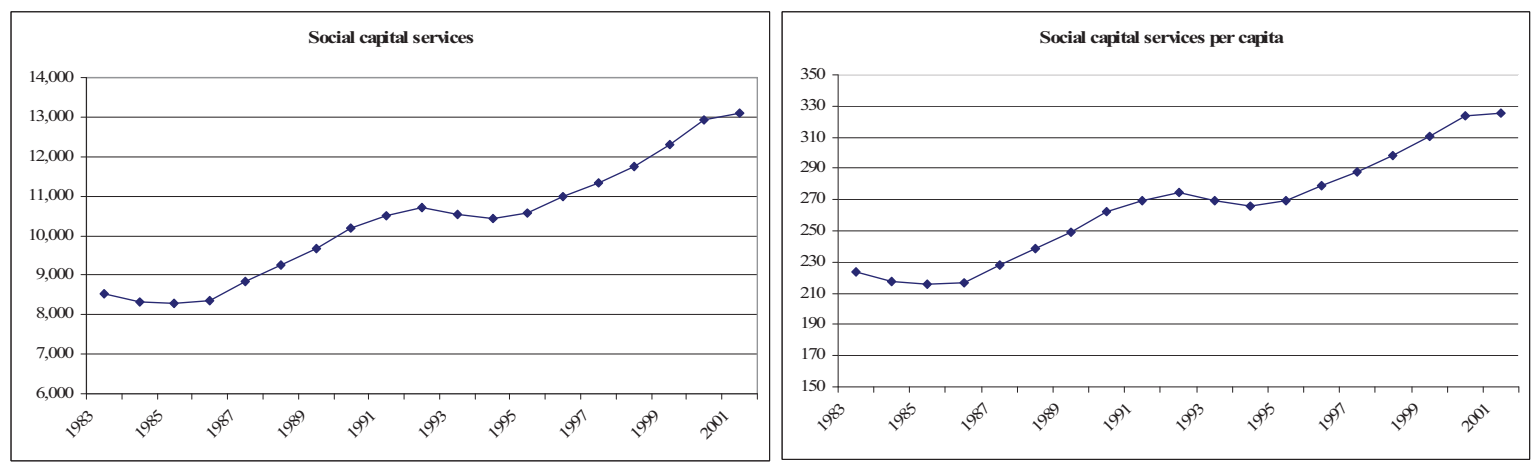

Source: IVIE

Figure 2. Regional distribution of social capital services per head. Spain.

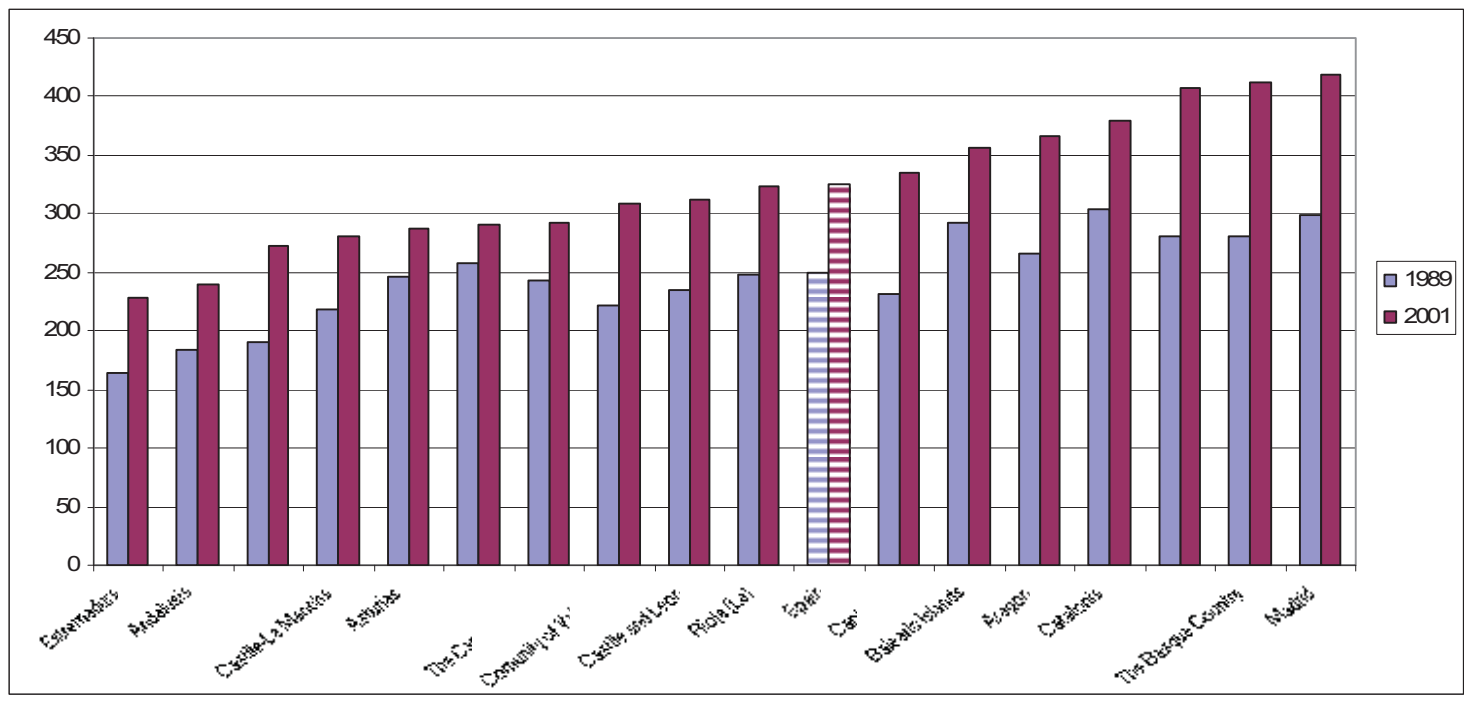

Source: IVIE

Figure 3. Spanish evolution of patent applications (1989-2001)

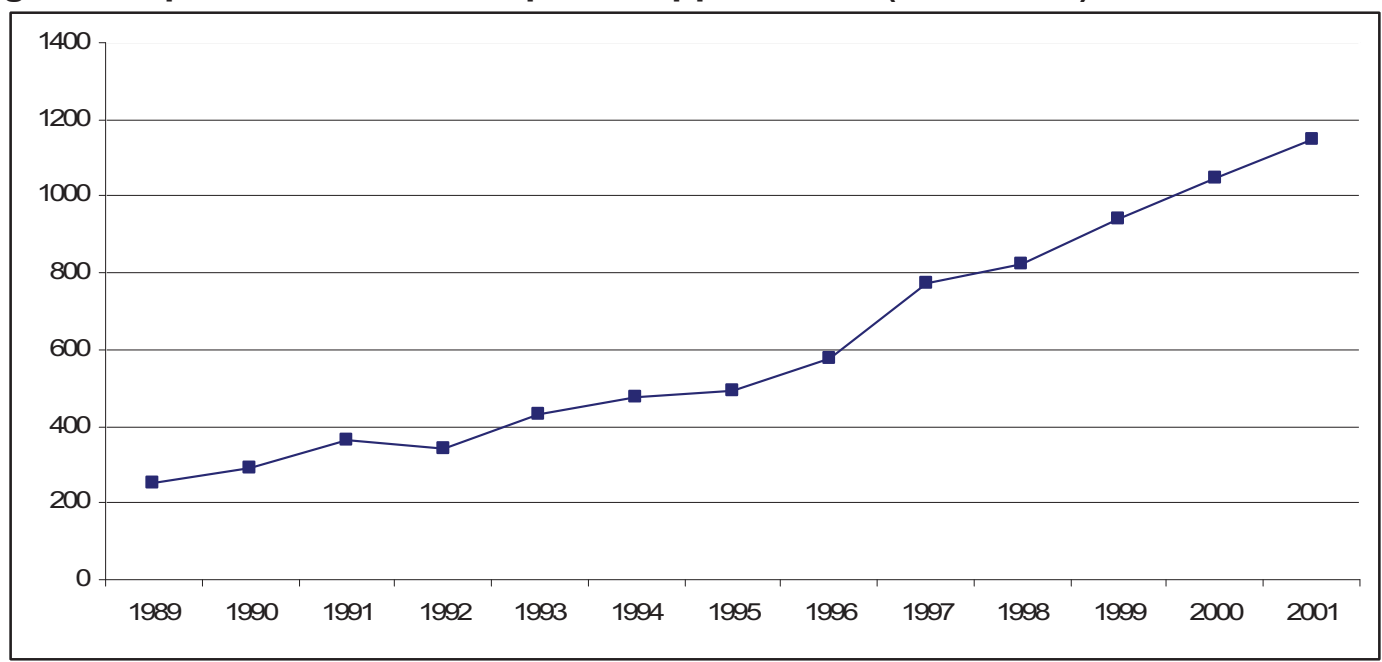

Source: European Patent Office (EPO) 
Table 1. Description of main variables in the analysis

\begin{tabular}{|c|c|c|c|c|c|c|c|c|}
\hline & \multirow{2}{*}{$\begin{array}{c}\text { Patents 1989-2001 } \\
\text { Regional distribution }\end{array}$} & \multicolumn{2}{|c|}{ Social capital 1989-2001 } & \multicolumn{3}{|c|}{ R\&D expenditures 1989-2001 } & \multicolumn{2}{|c|}{ Human capital 1989-2001 } \\
\hline & & $\begin{array}{l}\text { Per capita social } \\
\text { capital } 2001\end{array}$ & $\begin{array}{l}\text { Social capital } \\
\text { growth }\end{array}$ & $\begin{array}{c}\text { R\&D per capita } \\
2001\end{array}$ & $\begin{array}{c}\text { Regional } \\
\text { distribution }\end{array}$ & $\begin{array}{l}\mathrm{R} \& \mathrm{D} p \mathrm{pc} \\
\text { growth }\end{array}$ & $\begin{array}{c}\text { Human capital } \\
2001\end{array}$ & $\begin{array}{l}\text { Human capital } \\
\text { growth }\end{array}$ \\
\hline Andalusia & 5.34 & 239.78 & 1.92 & 55.21 & 9.05 & 6.53 & 17.67 & 4.14 \\
\hline Aragon & 3.42 & 366.05 & 2.32 & 87.11 & 2.41 & 5.43 & 20.61 & 4.82 \\
\hline Asturias & 1.19 & 287.14 & 0.91 & 67.97 & 1.60 & 6.52 & 17.69 & 4.57 \\
\hline Balearic Islands & 0.84 & 356.93 & 1.90 & 32.69 & 0.49 & 10.41 & 14.22 & 3.40 \\
\hline The Canary Islands & 1.10 & 291.71 & 1.81 & 57.29 & 1.99 & 11.87 & 15.22 & 1.88 \\
\hline Cantabria & 0.53 & 335.85 & 3.23 & 64.71 & 0.80 & 4.76 & 15.53 & 2.41 \\
\hline Castile and Leon & 2.55 & 312.76 & 1.98 & 89.04 & 4.04 & 7.87 & 19.55 & 5.04 \\
\hline Castile-la Mancha & 1.14 & 280.44 & 1,76 & 30.73 & 1.38 & 9.45 & 15.77 & 5.36 \\
\hline Catalonia & 37.90 & 379.77 & 1.62 & 153.86 & 20.98 & 5.90 & 19.45 & 4.21 \\
\hline Comunity of Valencia & 10.21 & 309.41 & 2.42 & 82.01 & 6.30 & 9.44 & 17.52 & 4.92 \\
\hline Extremadura & 0.36 & 228.91 & 1.97 & 46.37 & 0.79 & 9.40 & 17.00 & 4.65 \\
\hline Galicia & 1.59 & 290.23 & 0.93 & 65.27 & 3.13 & 11.15 & 15.27 & 6.57 \\
\hline Madrid & 22.04 & 418.05 & 2.44 & 280.49 & 35.16 & 2.95 & 30.29 & 4.35 \\
\hline Murcia & 1.09 & 273.01 & 2.83 & 62.49 & 1.49 & 6.27 & 18.25 & 4.95 \\
\hline Navarre & 3.08 & 407.40 & 3.29 & 145.62 & 1.63 & 11.80 & 24.02 & 4.71 \\
\hline The Basque Country & 7.33 & 412.40 & 3.16 & 195.02 & 8.46 & 6.39 & 23.55 & 3.87 \\
\hline La Rioja & 0.29 & 322.82 & 2.31 & 60.52 & 0.31 & 14.41 & 18.38 & 4.09 \\
\hline Total & 100 & 325.23 & 1.99 & 113.89 & 100 & 5.63 & 19.94 & 4.53 \\
\hline
\end{tabular}

Note: Growth rates are calculated as accumulative annual growth rates

Source: Own calculations from different datasets 
Table 2. Regression results for the negative binomial model with random effects. Dependent variable: number of patents

\begin{tabular}{|c|c|c|c|c|}
\hline & (i) & (ii) & (iii) & (iv) \\
\hline \multirow[t]{2}{*}{ Constant } & $-9.46 * * *$ & $-13.5 * * *$ & $-13.8 * * *$ & $-14.1 * * *$ \\
\hline & $(0.860)$ & $(2.625)$ & (3.376) & $(3.361)$ \\
\hline \multirow[t]{2}{*}{$\ln (\mathrm{RD})$} & $0.323 * * *$ & $0.272 * *$ & $0.685 * *$ & 0.395 \\
\hline & (0.106) & $(0.111)$ & $(0.292)$ & $(0.403)$ \\
\hline \multirow[t]{2}{*}{$\ln (\mathrm{HK})$} & $0.736 * *$ & $2.248 * *$ & $0.731 * *$ & 1.982 \\
\hline & $(0.297)$ & $(0.964)$ & $(0.296)$ & (1.276) \\
\hline \multirow[t]{2}{*}{$\ln (\mathrm{SK})$} & $0.737 * * *$ & $1.425 * * *$ & $1.438 * * *$ & $1.525 * * *$ \\
\hline & $(0.167)$ & (0.449) & $(0.547)$ & $(0.548)$ \\
\hline \multirow[t]{2}{*}{$\ln (\mathrm{SK}) * \ln (\mathrm{HK})$} & & $-0.22 *$ & & -0.189 \\
\hline & & $(0.139)$ & & $(0.187)$ \\
\hline \multirow[t]{2}{*}{$\ln (\mathrm{SK}) * \ln (\mathrm{RD})$} & & & -0.059 & -0.018 \\
\hline & & & $(0.044)$ & $(0.058)$ \\
\hline \multirow[t]{2}{*}{$\ln (\mathrm{MAN})$} & $0.763 * * *$ & $0.725 * * *$ & $0.785 * * *$ & $0.738 * * *$ \\
\hline & $(0.151)$ & $(0.150)$ & $(0.153)$ & $(0.156)$ \\
\hline \multirow[t]{2}{*}{$\ln (\mathrm{SpIn})$} & 0.312 & 0.269 & 0.344 & 0.286 \\
\hline & $(0.224)$ & $(0.222)$ & $(0.227)$ & $(0.229)$ \\
\hline \multirow[t]{2}{*}{$\ln (\mathrm{POP})$} & 0.085 & 0.120 & 0.122 & 0.125 \\
\hline & $(0.101)$ & $(0.101)$ & $(0.106)$ & $(0.103)$ \\
\hline \multirow[t]{2}{*}{ Time trend } & $0.071 * * *$ & $0.077 * * *$ & $0.075 * * *$ & $0.077 * * *$ \\
\hline & $(0.013)$ & $(0.013)$ & (0.013) & $(0.013)$ \\
\hline \multicolumn{5}{|l|}{ Total semi-elasticity with respect to } \\
\hline $\mathrm{RD}$ & $0.323 * * *$ & $0.272 * *$ & $0.326 * * *$ & $0.282 * *$ \\
\hline$\left[\beta^{\mathrm{RD}}+\beta^{\mathrm{RD} \mathrm{SK}} \ln (\mathrm{SK})\right]$ & $(0.106)$ & $(0.111)$ & $(0.107)$ & $(0.115)$ \\
\hline $\mathrm{HK}$ & $0.736 * *$ & $0.860 * * *$ & $0.731 * *$ & $0.836 * * *$ \\
\hline$\left[\beta^{\mathrm{HK}}+\beta^{\mathrm{HK} \cdot \mathrm{SK}} \ln (\mathrm{SK})\right]$ & $(0.297)$ & $(0.305)$ & $(0.296)$ & $(0.313)$ \\
\hline SK & $0.737 * * *$ & $0.821 * * *$ & $0.771 * * *$ & $0.817 * * *$ \\
\hline$\left[\beta^{\mathrm{SK}}+\beta^{\mathrm{RDSK}} \ln (\mathrm{RD})+\beta^{\mathrm{HK} \cdot \mathrm{SK}} \ln (\mathrm{HK})\right]$ & $(0.167)$ & $(0.173)$ & $(0.168)$ & $(0.173)$ \\
\hline Sample size & 221 & 221 & 221 & 221 \\
\hline Log-likelihood & -646.841 & -645.474 & -645.929 & -645.424 \\
\hline Wald test & 1324.830 & 1304.990 & 1305.540 & 1302.670 \\
\hline Prob & 0.0000 & 0.0000 & 0.0000 & 0.0000 \\
\hline \multicolumn{5}{|l|}{ Panel vs. Pooled } \\
\hline Chi2 & 151.56 & 154.26 & 104.80 & 91.81 \\
\hline Prob.: & 0.000 & 0.000 & 0.000 & 0.000 \\
\hline \multicolumn{5}{|l|}{ Hausman test } \\
\hline$\overline{\text { Chi2 }}$ & 5.62 & 4.54 & 4.37 & 4.16 \\
\hline Prob.: & 0.5849 & 0.8049 & 0.8227 & 0.9006 \\
\hline
\end{tabular}

Notes: Random effects model with several levels of significance: $1 \% * * * ; 5 \% * * ; 10 \% *$

Standard errors are presented in italics and parenthesis below each associated parameter

The average values to calculate the semi-elasticities are: $\ln \& \& D=11.23 ; \ln H K=2.64 ; \operatorname{lnSK}=6.05$ 


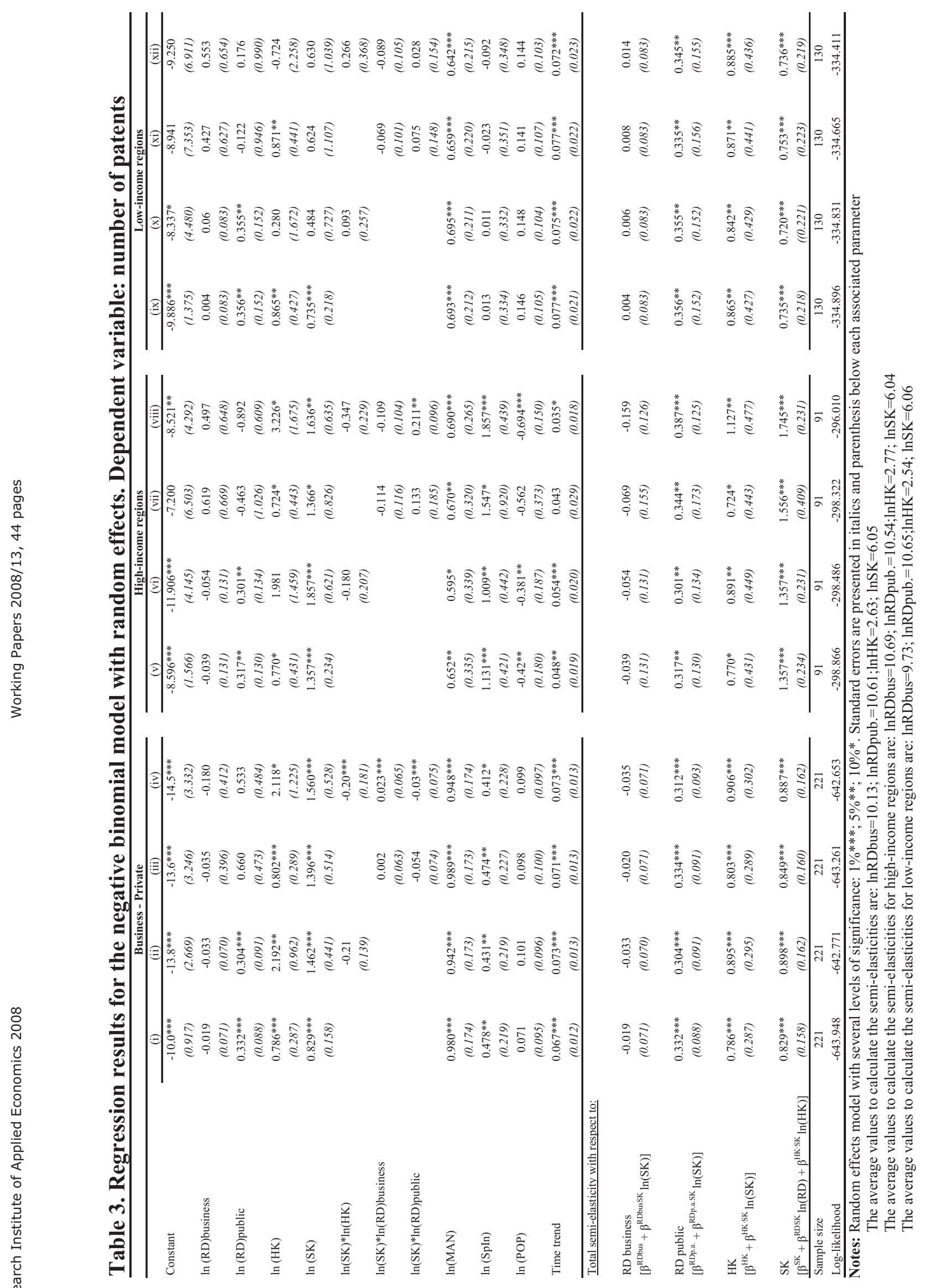




\footnotetext{
${ }^{1} \mathrm{http} / / /$ ec.europa.eu/growthandjobs/faqs/background/index_en.htm

${ }^{2}$ The specialization index has been built with Gross Added Value (GAV) data and takes the form of
}

$$
\operatorname{SpIn}_{i t}=\frac{1}{2} \sum_{j}\left|\frac{G A V_{i j}}{G A V_{i}}-\frac{G A V_{N j}}{G A V_{N}}\right|
$$

where $\mathrm{i}=$ region, $\mathrm{N}=$ nation, and $\mathrm{j}=$ economic sector.

${ }^{3}$ The World/European Values Survey was designed to enable a cross-national comparison of values and norms on a wide variety of topics and to monitor changes in values and attitudes across the globe. This data collection contains the survey data from the four waves of the World Values Survey and European Values Survey, carried out in 19811984, 1990-1993, 1995-1997 and 1999-2004. Broad topics covered in the integrated file include perception of life, family, work, traditional values, personal finances, religion and morals, the economy, politics and society, the environment, allocation of resources, contemporary social issues, national identity, and technology and its impact on society. The European coordination centre is located in Tilburg University, The Netherlands, whilst the Survey was extended globally by Ronald Inglehart from the University of Michigan (US).

${ }^{4}$ For a detailed explanation of this dataset and its modelling, see PÉREZ et al. (2005 and 2006), and for interesting empirical implementations of it, see PÉREZ et al. (2006), and PASTOR and TORTOSA-AusinA, (2007).

${ }^{5}$ As BALtAGi (2005) summarizes, panel data allow one to control for individual heterogeneity, whilst cross-section and time-series studies do not, taking into account regional time-invariant characteristics within the considered period. Moreover, longitudinal studies "give more information data, more variability, less collinearity among the variables, more degrees of freedom and more efficiency" (BALTAGI, 2005; p. 5) providing less biased, and more consistent estimations of the relationships between innovative inputs and their output, which might be considered an important gap in the previous literature on this topic.

${ }^{6}$ According to some scholars, the difference between patent applications and granted patents is not noteworthy neither in absolute quantities nor in terms of weights between regions and economic branches.

${ }^{7}$ Although our preferred aggregation level of analysis would have been the Spanish province (corresponding to NUTS3), given that it is both an appropriate unit of analysis within innovation and knowledge diffusion literature (RONDÉ and HussLer, 2005; ANSELIN et al., 1997; ACS et al., 2002), our analysis will be performed at the NUTS2 level due to a lack of available data on R\&D expenditure.

8 BDMORES database is provided by the Spanish Ministry of Economy at the following website: http://www.sgpg.pap.meh.es/SGPG/Cln_Principal/Presupuestos/Documentacion/Basesdatosestudiosregionales.htm 


\footnotetext{
${ }^{9}$ The high-income region sample includes Aragon, Balearic Islands, Catalonia, Madrid, Navarre, the Basque Country and La Rioja, whilst the low-income region sample includes Andalusia, Asturias, the Canary Islands, Cantabria, Castile and Leon, Castile-La Mancha, Community of Valencia, Extremadura, Galicia and Murcia.
} 